\title{
BMI in Childhood and Its Association with Height Gain, Timing of Puberty, and Final Height
}

\author{
QING HE AND JOHAN KARLBERG \\ Department of Pediatrics, The University of Hong Kong, Hong Kong SAR, P R China
}

\begin{abstract}
ABST
No large population-based study has addressed the question
of how overnutrition is related to subsequent height gain in
childhood, timing of puberty, and final height. The present data
represent a large Swedish population-based longitudinal growth
study. Height gain in childhood, timing of reaching peak height
velocity and height gain during adolescence, and final height
were regarded as the short-term, interim, and long-term out-
comes of childhood nutritional status, i.e. body mass index
(BMI) change between 2 and 8 y. Midparental height was
adjusted as the genetic influence on linear growth of the child.
Childhood BMI gain was related to an increased height gain
during the same period, i.e. an increase of 1 BMI unit was
associated with an increase in height of 0.23 cm in boys and 0.29
cm in girls. A higher BMI gain in childhood was related to an
earlier onset of puberty; the impact on the timing of puberty was
0.6 y in boys and 0.7 y in girls. Each increased unit of BMI gain
\end{abstract}
It is known that adequate nutrition is needed for normal growth during the pediatric years $(1,2)$. Some earlier studies of pediatric subjects also seem to support the hypothesis that overnutrition not only produces a normal growth but also accelerates linear growth $(3,4)$. Earlier studies were based on inpatient or outpatient series, and the number of subjects was relatively small. One study explored the association between obesity and height throughout childhood and adolescence (5); the obese subjects were seen to be taller than average in childhood, whereas during puberty they demonstrated a smaller growth spurt when compared with lean subjects. The series was taken from an obesity clinic, and the follow-up period was relatively short.

The objective of this study is to investigate the association between BMI change in childhood, i.e. from 2 to $8 \mathrm{y}$ of age, and gain in height during childhood, the timing of the puberty growth spurt, i.e. the age at PHV during puberty, and final height. The linear growth data were obtained from a popula-

Received March 2, 2000; accepted September 7, 2000.

Correspondence and reprint requests: Johan Karlberg, Department of Pediatrics, Queen Mary Hospital, The University of Hong Kong, Pokfulam, Hong Kong SAR, P.R. China. Supported by grants from the Faculty of Medicine, The University of Hong Kong, Hong Kong SAR, The Swedish Medical Research Council (\#7905), and Pharmacia Upjohn Inc, Stockholm, Sweden. in childhood also reduced the height gain in adolescence, 0.88 $\mathrm{cm}$ for boys and $0.51 \mathrm{~cm}$ for girls. No direct correlation was shown between childhood BMI gain and final height. We conclude that overnutrition between 2 and 8 y of age will not be beneficial from a final height point of view, as the temporary increase in height gain in childhood will be compensated by an earlier pubertal maturity and a subnormal height gain in adolescence. (Pediatr Res 49: 244-251, 2001)

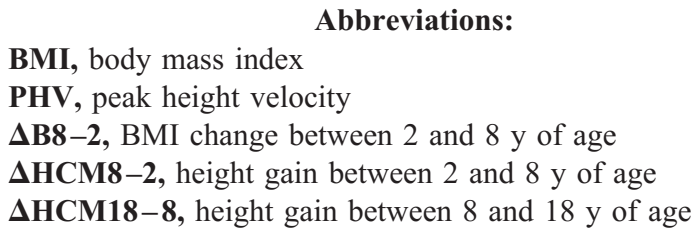

tion-representative longitudinal growth study of 3650 healthy children born at full-term between 1973 and 1975 in Göteborg, Sweden (6).

\section{METHODS}

Study population. The study subjects were selected from 5111 final grade-school children born in the early 1970s in Göteborg, Sweden, or the surrounding area of the city. The annual birth rate in Göteborg is around 4000 to 5500 newborns in the 0.5 million population. More than $98 \%$ of children between the ages of 17 and 19 remain within the school system in Sweden, including those with mild or moderate mental health problems.

Information on 319 girls and 304 boys was not obtained because some of them were not willing to do, or failed to attend, the last investigation at school; $76.8 \%$ of the remaining children $(n=4488)$ were born in $1974,16.7 \%$ in $1973,3.0 \%$ before 1973 , and $3.5 \%$ in 1975 . The exclusion criteria, such as multiple births, prematurity, growth disorders, and lack of information at birth, were applied in the selection of subjects (6). Children with allergic disease, such as asthma, were not excluded from the study population. The data in analysis therefore represents 3650 full-term (37-42 wk of gestation) 
and healthy Swedish children with growth information from birth to 18 y of age.

The data were collected from April to November 1992. The study team included four trained investigators and two school nurses. Health records for each child from birth to the last grade at school were retrieved when the study team visited the schools, all in Göteborg. These included any records made by doctors or nurses at the Child Health Centers (from birth to $6 \mathrm{y}$ of age) and at schools (from 7 to $18 \mathrm{y}$ of age). At each investigation, weight and height were measured in a standardized way for all school children. At the same time, the parents of each child were informed of the study and asked to report their current height and weight (6). The information of each child at birth and throughout the prenatal period, such as size at birth, length of gestation, and any health problems, was obtained from the Swedish Birth Register at the Swedish National Board for Health and Welfare.

Measurements. A computer-generated growth chart from birth to $18 \mathrm{y}$ of age was produced for each child. The height growth velocity $(\mathrm{mm} / \mathrm{y})$ curve was smoothed by the spline function. Such a velocity curve had enough values to be produced by $91.4 \%$ of the children in our study. The age at the peak of the height velocity curve during the adolescent period was identified optically and determined electronically by a digitizer connected to a computer; this age represents the age at PHV $(6,7)$.

A child who had reached the age of PHV within $2 \mathrm{y}$ from the final examination and had gained $<0.5 \mathrm{~cm}$ during the past year was regarded as having reached final height (6). All the children had reached the age of PHV $1.5 \mathrm{y}$ before the last examination, and had only limited growth left; $99.2 \%$ of our study population had reached final height at $18 \mathrm{y}$ of age when the study team visited the schools. Only 3 girls and 25 boys had not reached their final height at the last examination, which should have little influence on the findings of this study.

All growth data were computerized, and quality control analysis was performed. The weight and length of each child at birth were measured by trained midwives using exact measuring equipment. Before $2 \mathrm{y}$ of age, height was measured as supine length, and after $2 \mathrm{y}$ standing height was measured using a stadiometer attached to the wall. All height measurements were made to within $0.5 \mathrm{~cm}$. Measurements of children aged between 2 and 6 y of age were monitored by skilled personnel at the Child Health Monitoring Center, and after $6 \mathrm{y}$ by trained school nurses. Inasmuch as the measurements were routinely plotted on the individual child's growth chart, measuring errors could be found and corrected immediately. The precision of measurement is high at these centers, and in 70\% of the schools the difference of height values obtained from using the two measuring devices was $<2 \mathrm{~mm}(6)$.

This study was approved by the Ethical Committee of the Medical Faculty, the University of Göteborg, Sweden, and the Swedish Data Authorities. Written informed consent was received from children $>16 \mathrm{y}$, and from the parents of those younger than that.

Statistical analysis. Because most measurements were not taken at the exact age, a Statistical Analysis Software (SAS) program (8) was written to select the closest observation to each specified age automatically - within 1 mo during the first $2 \mathrm{y}$ of life and within 3 mo from age $3 \mathrm{y}$ onward. The selected ages $0,0.25,0.5,0.75,1.0,2.0,3.0,4.0,5.0,6.0,7.0,8.0,9.0$, $10.0,11.0,12.0,13.0,14.0,15.0,16.0,17.0$, and $18.0 \mathrm{y}$ of age were used to produce the individual height growth velocity $(\mathrm{mm} / \mathrm{y})$ curve that was used to identify the age of PHV.

BMI change between 2 and 8 y of age $(\Delta B 8-2)$ was defined as the childhood obesity pattern or adiposity rebound pattern together with the observed BMI in childhood in the present study. Height gain between 2 and 8 y of age $(\Delta H C M 8-2)$ was regarded as the short-term outcome measure; height gain between 8 and $18 \mathrm{y}$ of age $(\Delta \mathrm{HCM} 18-8)$ and the age of reaching the PHV were taken as the interim outcome measure, and final height was defined as the long-term outcome measure of the childhood obesity pattern. BMI at $8 \mathrm{y}$ of age was included as an independent measure as this measure reflects the nutritional status at the end of childhood, i.e. just before the onset of puberty. It seems to be realistic to adjust for BMI at this age because it may be the obtained BMI value rather than the change in the BMI value during the childhood years that is associated with the timing of puberty or the height gain during adolescence.

The children were divided into three different BMI change groups, according to the $\Delta \mathrm{B} 8-2$, i.e. decreasing $(\leq-2.5 \mathrm{~kg} /$ $\left.\mathrm{m}^{2}\right)$, intermediate $\left(-2.5\right.$ to $\left.0 \mathrm{~kg} / \mathrm{m}^{2}\right)$, and increasing $(>0$ $\mathrm{kg} / \mathrm{m}^{2}$ ). The children were also divided into three subgroups according to the age of reaching PHV. The two cutoff points were chosen approximately $0.5 \mathrm{y}$ around the mean $\mathrm{PHV}$ age (mean $\pm 0.5 \mathrm{y}$ ); i.e. at 13.4 and $14.4 \mathrm{y}$ of age for boys; and at $11.5 \mathrm{y}$ and 12.5 for girls. An ANOVA was used to compare the difference of the mean in $\triangle \mathrm{HCM} 8-2, \Delta \mathrm{HCM} 18-8$, and age of reaching $\mathrm{PHV}$ among three different $\mathrm{BMI}$ gain groups for boys and girls. A multiple linear regression analysis was applied to test the relationship between BMI change and its short-term, interim, and long-term effects. Midparental height, calculated as the average of the father's and mother's heights, is regarded as a better indicator of genetic potential height than either parent's individual height (9). It was taken as the measure of genetic influence on childhood height gain and final height in our regression analysis.

A statistically significant result was based on a $p$ value $<$ 0.05 . All statistical analyses were made in terms of the Statistical Analysis Software (SAS) version 6.10 (8).

\section{RESULTS}

The mean and SD of the measures are given in Table 1. The $\Delta$ B8 -2 was statistically different $(p<0.05)$ between boys and girls. Both the $\triangle \mathrm{HCM} 8-2$ and $\triangle \mathrm{HCM} 18-8$, were significantly different $(p<0.05)$ between the two sexes.

The children were divided into three different BMI change groups according to the $\Delta \mathrm{B} 8-2$, as described in the "Methods." The mean change in BMI is shown graphically in Figure 1 for the three groups for boys and girls separately. The mean BMI values at $18 \mathrm{y}$ of age are also displayed in Figure 1; the difference observed between each of the three groups at $8 \mathrm{y}$ of age seemingly remains into maturity. No significant difference (ANOVA, $p>0.05$ ) was found for the mean height at birth, 
Table 1. Growth measures for boys and girls

\begin{tabular}{|c|c|c|c|c|c|c|c|}
\hline \multirow[b]{2}{*}{ Variable } & \multirow[b]{2}{*}{$n$} & \multirow[b]{2}{*}{ Mean } & \multirow[b]{2}{*}{$\mathrm{SD}$} & \multicolumn{3}{|c|}{ Centile } & \multirow{2}{*}{$\begin{array}{c}p \\
\text { value } \|\end{array}$} \\
\hline & & & & 5 & 50 & 95 & \\
\hline \multicolumn{8}{|l|}{ Boys } \\
\hline HCM8 $(\mathrm{cm})^{*}$ & 1703 & 130.42 & 5.52 & & & & 0.0003 \\
\hline $\operatorname{HCM} 18(\mathrm{~cm})^{*}$ & 1854 & 180.41 & 6.58 & & & & 0.0001 \\
\hline$\Delta \mathrm{HCM} 8-2(\mathrm{~cm})$ & 1441 & 42.32 & 3.50 & & & & 0.01 \\
\hline B2 $\left(\mathrm{kg} / \mathrm{m}^{2}\right) \ddagger$ & 1449 & - & - & 15.09 & 17.10 & 19.51 & 0.0001 \\
\hline $\mathrm{B} 8\left(\mathrm{~kg} / \mathrm{m}^{2}\right) \dagger$ & 1699 & - & - & 13.90 & 15.75 & 18.66 & 0.22 \\
\hline B18 $\left(\mathrm{kg} / \mathrm{m}^{2}\right) \div$ & 1841 & - & - & 18.57 & 21.82 & 26.91 & 0.0001 \\
\hline$\Delta \mathrm{B} 8-2\left(\mathrm{~kg} / \mathrm{m}^{2}\right)$ & 1434 & - & - & -3.36 & -1.28 & 1.18 & 0.0001 \\
\hline MIDHEI $(\mathrm{cm}) \S$ & 1386 & 173.01 & 5.15 & & & & 0.23 \\
\hline \multicolumn{8}{|l|}{ Girls } \\
\hline $\mathrm{PHV}(\mathrm{y}) \dagger$ & 1651 & 11.96 & 0.98 & & & & \\
\hline B2 $\left(\mathrm{kg} / \mathrm{m}^{2}\right) \ddagger$ & 1439 & - & - & 14.76 & 16.77 & 19.20 & \\
\hline B8 $\left(\mathrm{kg} / \mathrm{m}^{2}\right) \dagger$ & 1679 & - & - & 13.64 & 15.68 & 19.05 & \\
\hline B18 $\left(\mathrm{kg} / \mathrm{m}^{2}\right) \ddagger$ & 1773 & - & - & 18.33 & 21.38 & 26.77 & \\
\hline$\Delta \mathrm{B} 8-2\left(\mathrm{~kg} / \mathrm{m}^{2}\right)$ & 1422 & - & - & -3.02 & -1.06 & 1.73 & \\
\hline MIDHEI $(\mathrm{cm}) \S$ & 1434 & 173.23 & 4.96 & & & & \\
\hline
\end{tabular}

* Height at 2,8 , and $18 \mathrm{y}$ of age.

$\dagger$ Age of reaching PHV.

$\$$ BMI value $\left(\mathrm{kg} / \mathrm{m}^{2}\right)$ at 2,8 and 18 years of age.

$\S$ Midparental height $=($ father's height + mother's height $) / 2$.

- Centile values were given for BMI at 2, 8, 18 y and for BMI change between 2 and 8 y because of their non-normal distribution.

$\|$ The $p$ value of $t$ test or the signed rank test (for non-normal statistical distribution) to compare the difference in the central tendency of the distribution of some variables between boys and girls.

nor at 18 y of age, among the three different childhood BMI change groups, for either of the two sexes. However, a significant difference was noted in the mean height at both 2 and $8 \mathrm{y}$ of age (ANOVA, $p<0.05$ ) among the three childhood BMI change groups (Fig. 2).

A multiple linear regression model was fitted to the series with the $\triangle$ HCM8 -2 as the dependent variable for both sexes (Table 2). All independent variables included in the regression model were continuous measures. They were all found to be statistically significant $(p<0.05)$, and taken together they gave an $r^{2}$ value of 0.21 for both boys and girls. Both BMI at $2 \mathrm{y}$ of age and the $\Delta \mathrm{B} 8-2$ were positively $(p<0.05)$ associated with the $\triangle \mathrm{HCM} 8-2$.

The $\Delta$ HCM $8-2$ and the $\Delta \mathrm{B} 8-2$ were both negatively associated $(p<0.05)$ with the age at reaching PHV for the two sexes (Table 3). BMI at $2 \mathrm{y}$ of age (model 1) and BMI at $8 \mathrm{y}$ of age (model 2) were negatively associated with the age at reaching PHV for boys only $(p<0.05)$.

The $\Delta$ HCM18-8 served as the dependent variable for additional liner regression models (Table 4). Judged on the estimated $t$ value of each independent measure, the age of reaching PHV was the most important variable included in the model for $\Delta \mathrm{HCM} 18-8$ for both sexes. Both BMI at $2 \mathrm{y}$ and BMI at 8 y were negatively $(p<0.05)$ associated with the $\Delta$ HCM18-8. A sex difference can be noted for the association between the $\Delta \mathrm{B} 8-2$ and $\Delta \mathrm{HCM} 18-8$ when BMI value at $8 \mathrm{y}$ was taken into consideration.
A final multiple linear regression model was fitted to the series, with the final height as the dependent variable for both sexes (Table 5). All independent variables in the regression models were statistically significant $(p<0.05)$, except for the $\mathrm{BMI}$ value at $18 \mathrm{y}$ of age for the two sexes and $\Delta \mathrm{B} 8-2$ for girls, giving an $r^{2}$ value of 0.74 for both boys and girls. In general, childhood nutritional status, i.e. BMI at $2 \mathrm{y}, 8 \mathrm{y}$, and the $\Delta \mathrm{B} 8-2$, was negatively associated with final height after adjustment of the other potential covariates.

All these regression models (Tables 2-5) have been retested after being adjusted for midparental height (results not shown). The results were, however, similar to the ones given in Tables $2-5$.

The three childhood BMI change groups were each divided into three groups according to the observed BMI value at $2 \mathrm{y}$ of age. The cutoff points of the BMI value at $2 \mathrm{y}$ of age were 16 and $18 \mathrm{~kg} / \mathrm{m}^{2}$; approximately corresponding to the 25 th and 75th centile values for both boys and girls. A statistically significant difference in $\Delta$ HCM18-8 (ANOVA, $p<0.05$ ) was found between the three BMI groups at $2 \mathrm{y}$ for both sexes (Fig. $3)$. The negative trend $(p<0.05)$ in $\Delta \mathrm{HCM} 18-8$ within each subgroup of BMI at $2 \mathrm{y}$ is notable.

The values of the mean $\Delta \mathrm{HCM} 18-8$ were further compared among the three different childhood BMI change groups $(\Delta \mathrm{B} 8-2)$ after the age of reaching PHV was taken into consideration (Fig. 4). The three childhood BMI change groups were further divided according to the age of reaching PHV; i.e. 


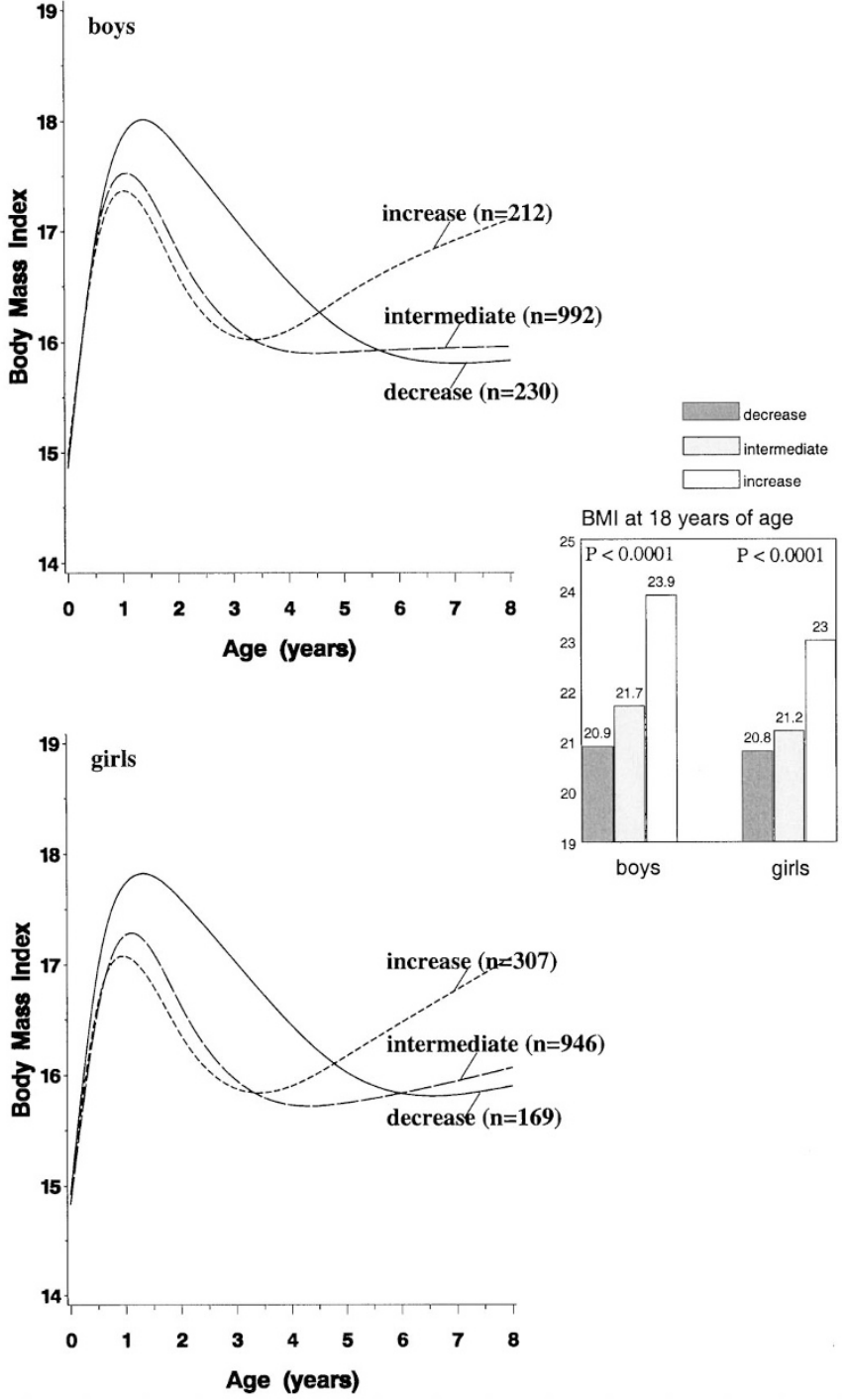

Fig. 1. BMI values from birth to $8 \mathrm{y}$ of age and BMI at $18 \mathrm{y}$ of age for Swedish boys and girls in relation to three different BMI change groups between 2 and 8 y of age, i.e. decrease $\left(\leq-2.5 \mathrm{~kg} / \mathrm{m}^{2}\right)$, intermediate $\left(-2.5\right.$ to $\left.0 \mathrm{~kg} / \mathrm{m}^{2}\right)$, and increase $\left(>0 \mathrm{~kg} / \mathrm{m}^{2}\right)$. The median BMI values at $18 \mathrm{y}$ of age are given for the three different childhood BMI change groups. The $p$ values refer to the Kruskal-Wallis test to compare the differences in central tendency distribution of BMI at $18 \mathrm{y}$ among the three childhood BMI change groups for both sexes.

approximately $0.5 \mathrm{y}$ around the mean PHV age formed the cutoff points. A statistically significant difference (ANOVA, $p<0.05$ ) was found in the mean height gain among the three PHV age groups. Within the three PHV age groups for each sex, a positive trend $(p<0.05)$ in adolescent height gain is observed.

\section{DISCUSSION}

Overnutrition or obesity in childhood has more recently become a worldwide health concern (10). It is known that childhood obesity is related to several adverse physical and psychosocial development consequences, and that the obese child has a higher risk of being obese into adulthood (11-13). However, less or very little is known about the association
Three BMI change $\left(\mathrm{kg} / \mathrm{m}^{2}\right)$ groups between 2 and 8 years of age

$\square<=-2.5 \square-2.5$ to $0 \square>0$
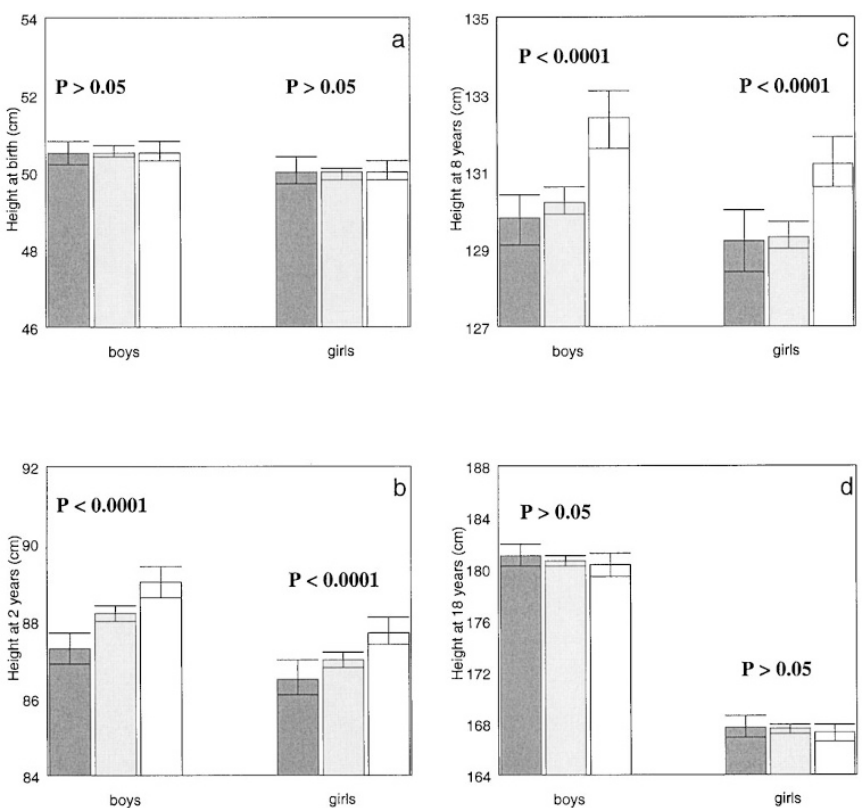

Fig. 2. The mean and its $95 \%$ confidence interval of height at (a) birth, (b) $2 \mathrm{y}$, (c) $8 \mathrm{y}$, and (d) $18 \mathrm{y}$ of age in relation to the three different childhood BMI change groups for both boys and girls. The $p$ values refer to the ANOVA to compare the differences in central tendency distribution of height at various ages among the three childhood BMI change groups.

between childhood overnutrition or obesity and subsequent height gain in childhood and adolescence, including the timing of puberty.

The main results of our study are of four kinds: childhood nutritional status is 1 ) related to an increased height gain in childhood, 2) related to an earlier timing of puberty, 3) related to a reduced height gain in adolescence after adjustment for the age of PHV, and 4) not directly related to final height.

Studies that support the hypothesis that overnutrition accelerates linear growth were reported in the 1960s and 1970s (3, 14). Most of these studies were performed on obese children being treated voluntarily at pediatric clinics. The sample size of these studies was also relatively small, and the period of follow-up was restricted to a few years. The data used in our study came from a large longitudinal population-based growth study of Swedish children followed from birth to $18 \mathrm{y}$ of age. The children were born in the early 1970s. Because of the unique Swedish educational system, in which $>98 \%$ of children remain until they are 17-18 y of age, we have obtained the growth information of an almost complete cohort of 18-y-old children. Sample selection bias is thus not a problem in this study as $87.7 \%$ of the total target population participated. In general, the results of our study can thus be served as representative for the general population in the affluent society. The extremes of obesity and leanness are represented in our data, but not in the same extreme pattern as in pediatric clinics or in population-based series from other countries such as those in North America. However, confirming studies in other pediatric 
Table 2. A multiple linear regression model with the height gain between 2 to 8 y of age as the dependent variable

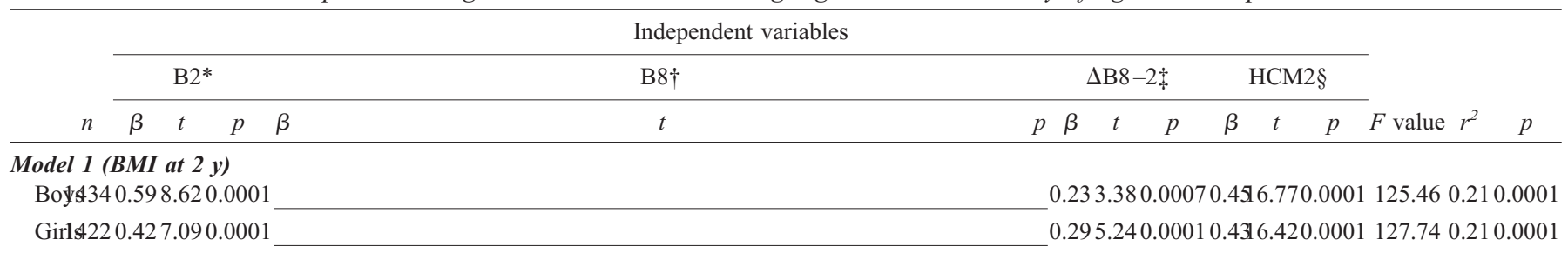

* BMI value $\left(\mathrm{kg} / \mathrm{m}^{2}\right)$ at $2 \mathrm{y}$ of age.

$\dagger$ BMI value $\left(\mathrm{kg} / \mathrm{m}^{2}\right)$ at $8 \mathrm{y}$ of age.

BMI change $\left(\mathrm{kg} / \mathrm{m}^{2}\right)$ between 2 and 8 y of age.

$\S$ Height $(\mathrm{cm})$ at $2 \mathrm{y}$ of age.

Table 3. Two different multiple linear regression models with the age at reaching PHV as the dependent variable

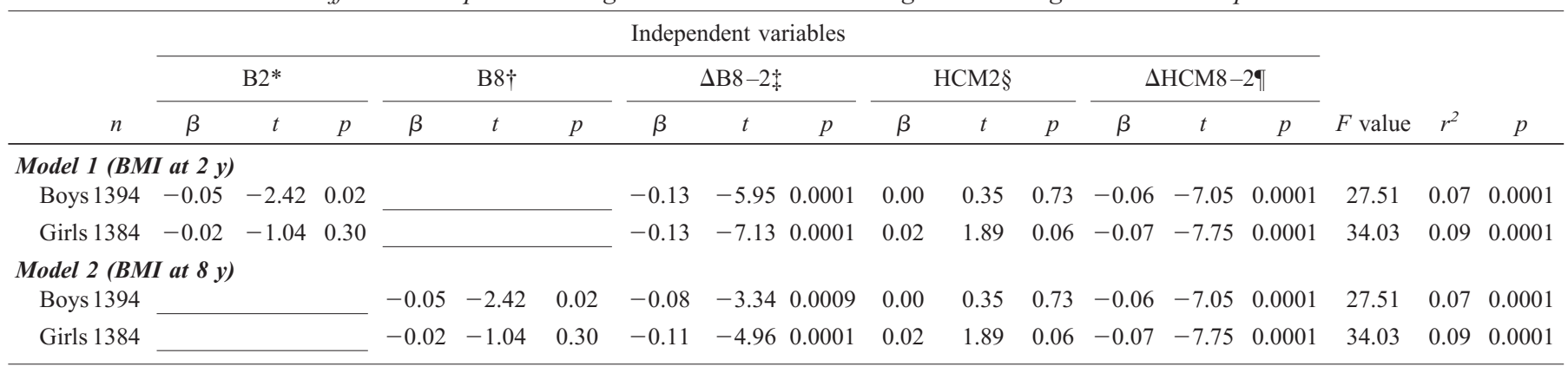

* BMI value $\left(\mathrm{kg} / \mathrm{m}^{2}\right)$ at $2 \mathrm{y}$ of age.

$\dagger$ BMI value $\left(\mathrm{kg} / \mathrm{m}^{2}\right)$ at $8 \mathrm{y}$ of age.

$\ddagger$ BMI change $\left(\mathrm{kg} / \mathrm{m}^{2}\right)$ between 2 and 8 y of age.

$\S$ Height $(\mathrm{cm})$ at 2 y of age.

T Height gain between 2 and $8 \mathrm{y}$ of age.

populations may be needed owing to the ethnic differences on human growth.

Our study focused on the postnatal linear growth in childhood, i.e. 2 to $8 \mathrm{y}$ of age, and in adolescence, i.e. $8 \mathrm{y}$ of age to final height. The main results were adjusted for BMI value at 2 y or 8 y of age.

It has been reported in previous studies that a strong correlation was found between GH binding protein and BMI, and children with obesity and normal growth have high GH receptor levels (15). A positive linear correlation has also been found between BMI and IGF-I levels $(r=0.51, p<0.05)(16)$. These findings imply that there is a relationship between serum growth factors, important for linear growth, and BMI in childhood.

In our study we simply used the $\Delta \mathrm{B} 8-2$ as a way to explore the adiposity rebound and its effect in later life $(17,18)$. Three different patterns of BMI change in childhood were identified (Fig. 1). It is interesting to note that the increased group remained as the one that reached the highest BMI value at $18 \mathrm{y}$ of age.

We found a significant positive association between the $\triangle \mathrm{B} 8-2$ and the $\triangle \mathrm{HCM} 8-2$, after adjusting for both the observed BMI value and measured height at 2 y of age. An increase of 1 BMI unit between 2 and $8 \mathrm{y}$ of age was associated with a gain in height of $0.23 \mathrm{~cm}$ in boys and $0.29 \mathrm{~cm}$ in girls during the same period. For the full range of BMI change in childhood in our study population, the effect on height gain was
$1.25 \mathrm{~cm}$ in boys and $1.75 \mathrm{~cm}$ in girls. The impact is significant but not impressive. However, the result supports the hypothesis that overnutrition accelerates linear growth in childhood. The result could also be seen in light of those from other studies, i.e. the BMI is positively correlated with serum IGF-I levels (16), and BMI is also positively correlated with the level of fasting serum insulin (19), which is suggested to play a key role in human growth, both directly and through increased free IGF-I secretion (20).

Our study results show a significant negative association between the $\triangle \mathrm{B} 8-2$ and the age of PHV after adjustment for both the observed BMI at 2 or $8 \mathrm{y}$ and measured height at $2 \mathrm{y}$ of age. An increase of 1 BMI unit between 2 and $8 \mathrm{y}$ of age was associated on average with a 0.11 y earlier timing of puberty, i.e. age of PHV for the two sexes. For the full range of BMI change in childhood of our study population, the effect on the timing of puberty was as large as $0.6 \mathrm{y}$ in boys and $0.7 \mathrm{y}$ in girls.

Our regression analysis revealed that the $\triangle \mathrm{HCM} 18-8$ was reduced by $1.25 \mathrm{~cm}$ in boys and $1.45 \mathrm{~cm}$ in girls for each year of earlier pubertal maturity (Table 4).

It has been documented that tall children typically enter puberty earlier than short children (21). It was also reported that Indian girls who were adopted during their infancy in Sweden had an earlier onset of puberty than the Swedish reference population (22). It is interesting to note their heights at onset of puberty were still below the reference mean, 


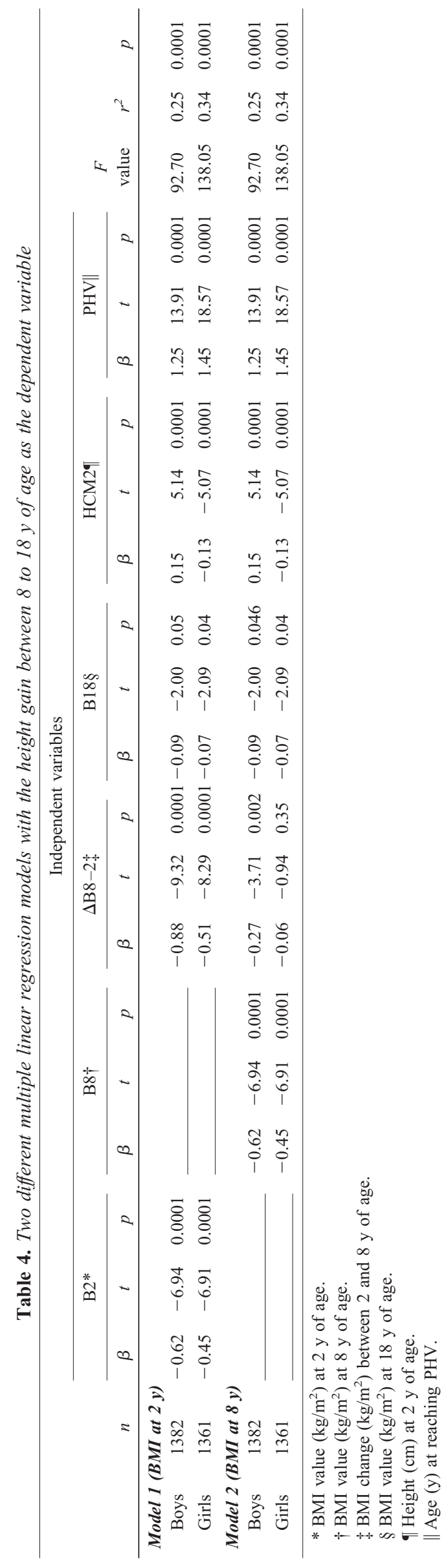

although they had a dramatic catch-up growth in childhood probably because of improved nutritional status. Our results are consistent with these previous studies, i.e. larger gain either in BMI or in height during childhood will induce an earlier onset of puberty (Table 3). This may be explained by the changes on the trigger mechanism of pubertal onset. Clayton et $a l$. reported the positive relationship between serum leptin and BMI through childhood and adolescence in their study of 235 healthy children from 5 to $18 \mathrm{y}$ of age. The similar rise in leptin during the prepubertal years into early puberty in both sexes, related not only to BMI but also independently to age, would suggest that leptin may have a facilitatory role in human pubertal development (23).

The $\Delta \mathrm{HCM} 18-8$ was also significantly and negatively associated with $\Delta \mathrm{B} 8-2$ adjusting for BMI and height at $2 \mathrm{y}$ of age (Table 4, model 1). Each increased unit of BMI gain in childhood reduced the height gain in adolescence $0.88 \mathrm{~cm}$ for boys and $0.51 \mathrm{~cm}$ for girls, corresponding to $4.79 \mathrm{~cm}$ and 3.08 $\mathrm{cm}$, respectively, for the full range of $\Delta \mathrm{B} 8-2$. However, when BMI value at $8 \mathrm{y}$ was taken into consideration (Table 4 , model 2), $\Delta \mathrm{B} 8-2$ became less of a contribution (evaluated by $t$ value) for boys or even became a nonsignificant $(p>0.05)$ independent variable for girls on the $\triangle \mathrm{HCM} 18-8$. Compared with boys, BMI value at $8 \mathrm{y}$ of age seemed more important than $\Delta \mathrm{B} 8-2$ for girls on the height gain during adolescence. This may be explained by the sex difference on body composition at 8 y of age.

To our knowledge, this is the first time that the association between childhood nutritional status (here, $\Delta \mathrm{B} 8-2$ ) and linear growth during adolescence has been estimated. It can be speculated that the children who have a large BMI gain in childhood will still have a high BMI during adolescence. These children may therefore have a relatively low level of GH, because the relationship between normal fat and physiologic GH secretion becomes inverse during puberty (24). It was also reported by Minuto et al. (25), based on their observation of 18 obese male subjects in different pubertal stages compared with 26 age-matched control subjects, that the pubertal growth spurt in obese subjects is at least less pronounced than in lean subjects. The conclusion of their study is that the GH and IGF-I secretion is impaired during puberty in obese subjects, leading to a reduced growth rate, whereas in the prepubertal period factors other than GH may replace or even potentate its action. One could also hypothesize that the growth process has an intrinsic program of cell division that is partly regulated by the internal milieu, such as nutrients, GH, insulin, and IGF-I; growth that has already taken place in childhood cannot occur in adolescence. This is supported by the advanced bone age observed in obese children (5).

Adiposity rebound in childhood is becoming an important and frequent pattern in most parts of the industrial world, and is known to be a solid predictor of obesity at a higher age and in adulthood. The effect of childhood adiposity rebound on subsequent height gain has not yet been characterized based on a large series, nor on a population-representative set of data. The present study clearly shows an association between the magnitude of childhood adiposity rebound in terms of 1) an increased height gain in childhood, potentially reflecting an 


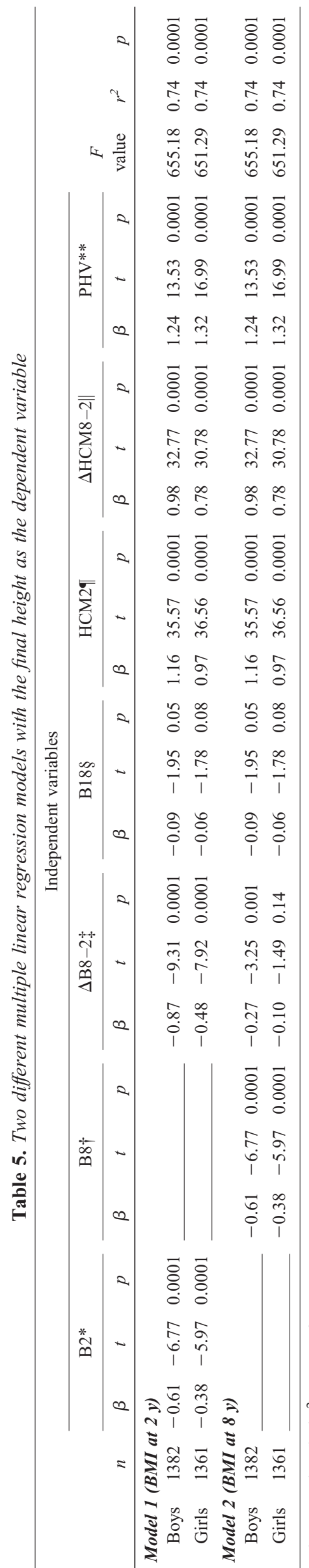

Three BMI change $\left(\mathrm{kg} / \mathrm{m}^{2}\right)$ groups between 2 and 8 years of age

$\square<=-2.5 \square$ to $0 \square>0$

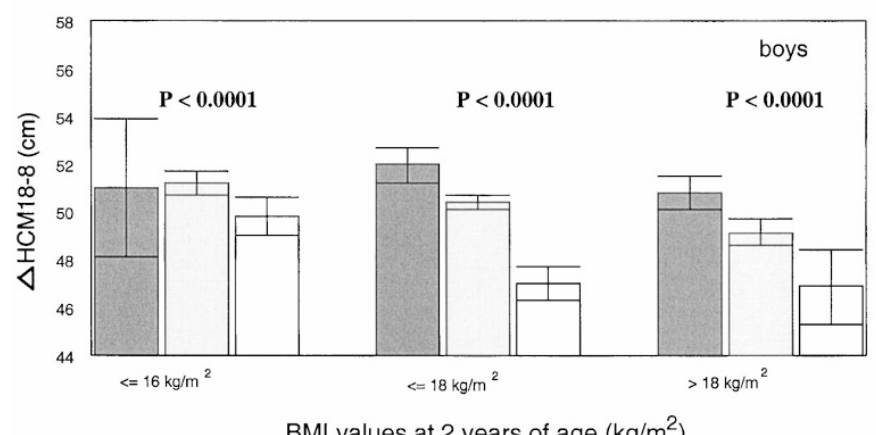

BMI values at 2 years of age $\left(\mathrm{kg} / \mathrm{m}^{2}\right)$

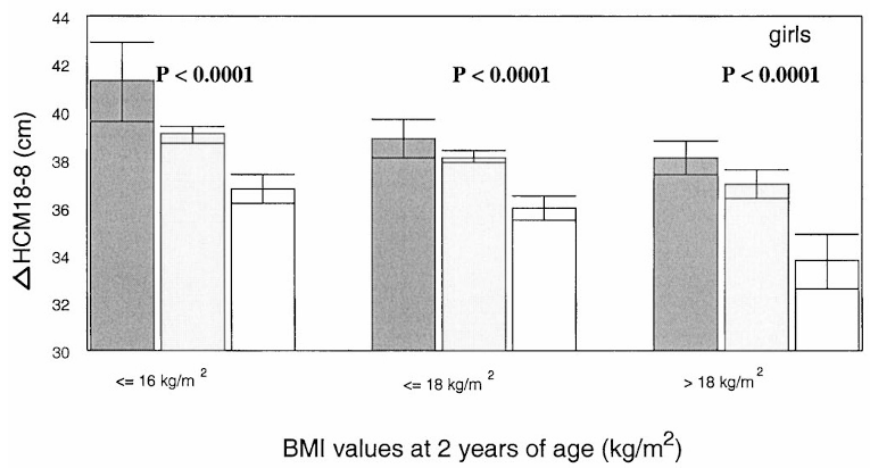

Fig. 3. The mean and its $95 \%$ confidence interval of $\triangle H C M 18-8$ for boys and girls in three different groups of BMI values at $2 \mathrm{y}$ of age. The cutoff points, 16 and $18 \mathrm{~kg} / \mathrm{m}^{2}$, represent the 25th and 75th centile values at $2 \mathrm{y}$ of age. Within each BMI group at $2 \mathrm{y}$, the values of height gain between 8 and $18 \mathrm{y}$ are also shown separately in three childhood BMI change groups. The $p$ values refer to the ANOVA to compare the differences in central tendency of height gain among the three BMI change groups.

increased secretion of IGF-I mediated by insulin and high GH-binding activity; 2) an earlier timing of puberty, potentially reflecting both the increased prepubertal height and metabolic changes or influence on the trigger mechanism of pubertal onset; and 3) a reduced height gain in adolescence, potentially reflecting an interaction with sex steroids or reduced GH during this phase of linear growth.

Partly similar conclusions were also reached in another previous study based on obese subjects $(5,26-28)$. However, the subjects in our study were representative of the normal population, so the pattern of the extremes of obesity and leanness represented in our data are not the same as the pattern in clinic- or hospital-based data sets.

Because postnatal linear growth is a complex result of the genetic, nutrition, and endocrine system, and BMI does not necessarily represent the true nutritional status of an individual, we cannot state from this study whether nutrition lacks an impact on skeletal growth during childhood, or whether it leads to any long-term consequences that persist into adulthood. The main result from the present study is that a larger gain of BMI in childhood, i.e. from 2 to 8 y of age, will not positively impact on final height, although there is a limited increase in height gain in childhood. Therefore, for those parents who 
Three BMI change $\left(\mathrm{kg} / \mathrm{m}^{2}\right)$ groups between 2 and 8 years of age
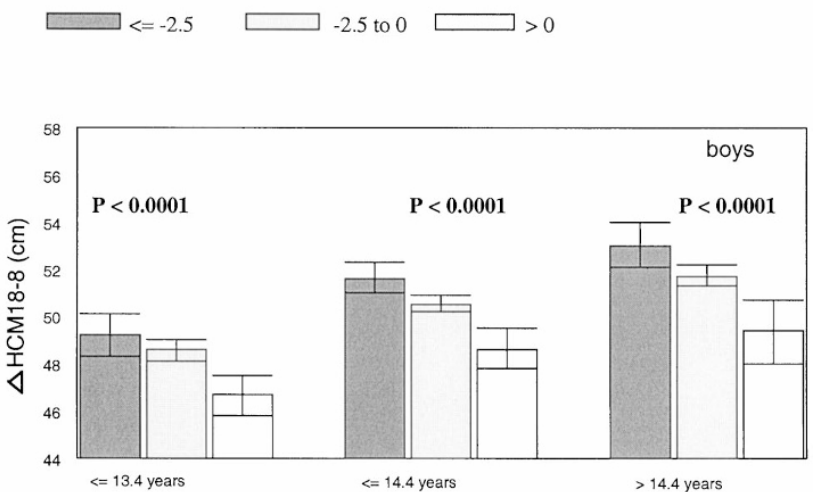

Age group at reaching peak height velocity (years)

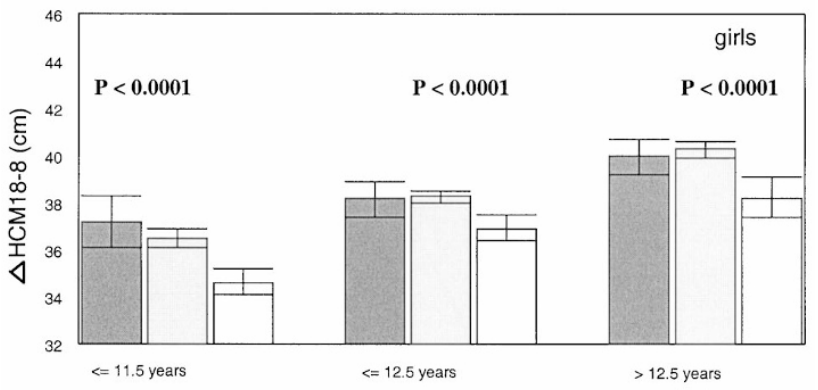

Age group at reaching peak height velocity (years)

Fig. 4. The mean and its $95 \%$ confidence interval of $\Delta H C M 18-8$ for boys and girls in three different age groups at reaching PHV. Within each PHV age group, the values of height gain between 8 and 18 y of age are also shown separately in three childhood BMI change groups. The $p$ values refer to the ANOVA to compare the differences in central tendency of height gain among the three BMI change groups.

want their children to be tall, overnutrition in childhood will not give much help, as the temporary increased height gain in childhood will be compensated by early pubertal maturation and a subnormal height gain in adolescence.

\section{REFERENCES}

1. Costello AM 1989 Growth velocity and stunting in rural Nepal. Arch Dis Child 64:1478-1482
2. Tse WY, Hindmarsh PC, Brook CG 1989 The infancy-childhood-puberty model of growth: clinical aspects. Acta Paediatr Scand Suppl 356:38-45

3. Forbes GB 1964 Lean body mass and fat in obese children. Pediatrics 34:308-314

4. Forbes GB 1977 Nutrition and growth. J Pediatr 91:40-42

5. De-Simone M, Farello G, Palumbo M, Gentile T, Ciuffreda M, Olioso P, Cinque M, De-Matteis F 1995 Growth charts, growth velocity and bone development in childhood obesity. Int J Obes Relat Metab Disord 19:851-857

6. Karlberg J, Albertsson-Wikland K 1995 Growth in full-term small-for-gestational-age infants: from birth to final height. Pediatr Res 38:1-7

7. Karlberg J 1989 A biologically-oriented mathematical model (ICP) for human growth. Acta Paediatr Suppl 350:70-94

8. SAS Institute Inc. 1996 SAS User's Guide: Statistics, Version 6.10 Ed. SAS Institute, Cary, NC

9. Luo ZC, Albertsson-Wikland K, Karlberg J 1998 Target height as predicted by parental heights in a population-based study. Pediatr Res 44:563-571

10. Delpeuch F, Maire B 1997 Obesity and developing countries of the south. Med Trop (Mars) 57:380-388

11. Abraham S, Nordseick M 1960 Relationship of excess weight in children and adults Public Health Rep 75:263-273

12. Lloyd JK, Wolff OH, Whelen WS 1961 Childhood obesity: a long-term study of height and weight. BMJ 2:145-148

13. Charney E, Goodman HC, McBride M, Lyon B, Pratt R 1976 Childhood antecedents of adult obesity: do chubby infants become obese adults? N Engl J Med 295:6-9

14. Cheek DB, Schultz RB, Parra A, Reba RC 1970 Overgrowth of lean and adipose tissues in adolescent obesity. Pediatr Res 4:268-279

15. Postel-Vinay MC, Saab C, Gourmelen M 1995 Nutritional status and growth hormone-binding protein. Horm Re 44:177-181

16. Bideci A, Cinaz P, Hasanoglu A, Elbeg S 1997 Serum levels of insulin-like growth factor-I and insulin-like growth factor binding protein-3 in obese children. J Pediatr Endocrinol Metab 10:295-299

17. Rolland-Cachera MF, Deheeger M, Bellisle F, Sempe M, Guilloud-Bataille M, Patois E 1984 Adiposity rebound in children: a simple indicator for predicting obesity. Am J Clin Nutr 39:129-135

18. Rolland-Cachera MF, Deheeger M, Guilloud-Bataille M, Avons P, Patois E, Sempe M 1987 Tracking the development of adiposity from one month of age to adulthood. Ann Hum Biol 14:219-229

19. Frystyk J, Vestbo E, Skjaerbaek C, Mogensen CE, Orskov H 1995 Free insulin-like growth factors in human obesity. Metabolism 44 (suppl 4):37-44

20. Yasunaga T, Furukawa S, Katsumata N, Horikawa R, Tanaka T, Tanae A, Hibi I 1998 Nutrition related hormonal changes in obese children. Endocr J 45:221-227

21. Karlberg J, Boepple PA 1993 Final height as reflected by prepubertal height and the timing of puberty. In: Grave GD, Cutler GB (eds). Sexual Precocity: Etiology, Diagnosis, and Management. Raven Press, New York, pp 85-95

22. Proos LA 1992 Growth and development of Indian children adopted in Sweden. Doctoral thesis at Uppsala University, Uppsala, pp 34-35

23. Clayton PE, Gill MS, Hall CM, Tillmann V, Whatmore AJ, Price DA 1997 Serum leptin through childhood and adolescence. Clin Endocrinol Oxf 46:727-733

24. Patel L, Skinner AM, Price DA, Clayton PE 1994 The influence of body mass index on growth hormone secretion in normal and short statured children. Growth Regu 4:29-34

25. Minuto F, Barreca A, Del-Monte P, Fortini P, Resentini M, Morabito F, Giordano G 1988 Spontaneous growth hormone and somatomedin-C/insulin-like growth factor-I secretion in obese subjects during puberty. J Endocrinol Invest 11:489-495

26. Vignolo M, Naselli A, Di-Battista E, Mostert M, Aicardi G 1988 Growth and development in simple obesity. Eur J Pediatr 147:242-244

27. Barbaglia M, Guzzaloni G, Moreni G, Ardizzi A, Morabito F 1990 Assessment of final body height of a group of persons with juvenile obesity. Minerva Pediatr 42:485-487

28. Barbaglia M, Ardizzi A, Guzzaloni G, Moreni G, Fatica P, Grugni G, Morabito F 1991 Growth in stature in infantile-juvenile obesity. Minerva Pediatr 43:433-436 